\title{
Consumption and the Constitution of Age: \\ Expenditure Patterns on Clothing, Hair and Cosmetics among Post-War 'Baby Boomers'
}

\section{Julia Twigg and Shinobu Majima}

University of Kent and Gakushuin University, Japan

\begin{abstract}
The article addresses debates around the changing nature of old age, using UK data on spending on dress and related aspects of appearance by older women to explore the potential role of consumption in the reconstitution of aged identities. Based on pseudo-cohort analysis of Family Expenditures Survey, it compares spending patterns on clothing, cosmetics and hairdressing, 1961-2011. It concludes there is little evidence for the 'baby boomers' as a strategic or distinctive generation. There is evidence, however, for increased engagement by older women in aspects of appearance: shopping for clothes more frequently; more involved in the purchase of cosmetics; and women over 75 are now the most frequent attenders at hairdressers. The roots of these patterns, however, lie more in period than cohort effects, and in the role of producer-led developments such as mass cheap fashion and the development of anti-ageing products.
\end{abstract}

Keywords: consumption, baby boomer, clothing, cosmetics, hairdressing

\section{Introduction}

The article addresses debates about the changing nature of old age and the potential role of consumption in this. It takes as its starting point work by Gilleard and Higgs (2000, 2013) and others who have argued that old age in the late twentieth/early twenty-first century has undergone a significant cultural shift associated with consumption, carried forward in particular by the 'baby boomer' generation. Most of such analyses concentrate on consumer durables and leisure. In this article we have 
focused instead on aspects of appearance and self-presentation in the form of spending on clothing, cosmetics and hairdressing for women. Closely linked to identity and selfhood, they offer a relevant arena in which to explore arguments about the changing meaning of later years, and shifting sources of identity and selfhood in late modern capitalist society. We shall use these data to question claims about a distinctive consumption generation.

\section{The reconstitution of ageing thesis}

The reconstitution of ageing thesis argues that old age has undergone a shift in the late twentieth century under the impact of changes in relation to work, the family and personal identity. The normative life course, established in the early years of the twentieth century across western economies (Anderson 1985), and broadly persisting in the UK until the 1980s, has been destabilised, giving ways to more fragmented individualised patterns. Traditional age ordering has weakened, with stages of life, and behaviour appropriate to them, less clearly prescribed. As a result later years are no longer the clearly defined, cultural scripted period, they once seemed.

These shifts support the emergence in across western economies of the Third Age as a distinct cultural space. A period post-retirement, freed from the constraints of work and, to some degree, family responsibility, it is marked by leisure, pleasure and self development. Defined as a state rather than an age, it roughly maps onto the fifties to seventies. The concept has been criticized: for describing the lives of a section of older people - the affluent middle class - and for presenting an aspirational version of this; for projecting the difficulties of old age into a dark Fourth Age of disability and decline; and, through its emphasis on choice and agency, implicitly providing an ideological support for a neo-liberal restructuring of the welfare state (Phillipson 1998, Walker 2012). Some theorists (Öberg \& Tornstram 1999, 2001) suggest the stage is better conceptualized in terms of an extended plateau of late middle years, that only ceases with the irruption of ill health and disability; and they link this to a declining salience of age ordering at all stages of life, with adulthood forming an undifferentiated period between childhood and frail old age.

The thesis is also linked to ideas concerning identity. Under conditions of post- or late-modernity, traditional formations of class, gender - and to a degree age - become 
less central, as identities are less socially entrenched, more the product of agency and choice. Consumption here assumes a new significance as a source of identity, performing an integrative function in an increasingly individualised culture (Giddens 1991, Bauman 2000, Paterson 2006). In relation to older people, consumption offers a possibility of counteracting the cultural exclusion traditionally associated with age, as they join younger cohorts in a common pursuit of consumption oriented lifestyles. Such integration, of course, rests on resources. Though in the period from the 1960s to today the incomes of some pensioners have risen, many remain in poverty, producing a dual trend in the UK, towards greater heterogeneity among older people, combined with greater similarity in relation to the general population. Jones and colleagues (2008) suggest that this dual pattern extends to cultural identity also.

Lastly these changes have occurred in the context of major demographic shift that has occurred across advanced western societies. In the UK, between 1901 and 2003 the proportion of the population aged 50 and over increased from 15 to 30 per cent; and it is projected to rise to 41 per cent in 2031 (Tomassini 2005). Though the shift is long term, it has been particularly pronounced recently with the passing through of the 'baby boomer' generation.

\section{'Babyboomers': a pioneer generation?}

Arguments about the changing nature of age are often associated with ideas of the 'baby boomers' as a 'special' or pioneering generation (Gilleard \& Higgs 2000, Biggs et al 2007). Edmunds and Turner (2002) describe them as a 'strategic generation in aesthetic, cultural and sexual terms...the first [...] to live through a time when mass consumer revolution transformed popular taste' (quoted by Phillipson 2007). Others have depicted them less flatteringly, as a narcissistic generation, greedy in their appropriation of resources, selfish in their pursuit of hedonistic individualism (Stewart \& Torges 2006, Willetts 2010).

The debate is confused by varying demographics in different western countries (Phillipson 2007). In the US, the home of the 'baby boomer' terminology, there was a sustained surge in births from the mid 1940s to the mid 1960s. In some European countries (Finland) (Karisto 2007), there was a peak immediate after the war; in others (Germany) there was no significant surge at all. The UK had a distinctive 
pattern of two separate peaks, one in the late forties, the other in the mid sixties. In line with other UK work, we focus on the first peak, previously known as the post-war 'bulge'.

A more sophisticated version of the baby boomer thesis is provided by Gilleard and Higgs in their concept of 'generational habitus'. (Gilleard \& Higgs 2002, 2007, Higgs et al 2009). They recognize the problems presented by the use of 'generation' as an analytic category: its imprecision; the varying and contentious nature of the factors underlying it; its assumption that events - usually on the world stage - have an impact on identity and consciousness; and its assumed homogeneity within the group. Drawing on Bourdieu, however, they argue for a concept of 'generational habitus' that arises from a particular generational field that develops through time. They suggest that 'people are not just affected by the historical period in which they grow up and live out their lives but that this set of circumstances also gives rise to a "generational style" which produces a distinct consciousness of those experiences' (Higgs et al 2009, p.105). They describe the 'generational habitus' of the generation who came to adulthood in the sixties as 'marked by rising living standards, the growth of consumer culture and the expansion of youth culture' producing a commodification of lifestyle and an erosion of status and tradition. (Higgs et al 2009 p106). The carriers of this 'generational habitus', they argue, are marked out from those who precede them; and they carry this difference with them as they grow old. In related empirical work, they attempt to demonstrate this generational effect through an analysis of UK Family Expenditures Survey (FES) data on consumer durables and leisure 1968-2005 (Jones et al 2009).

We too use FES data to interrogate ideas about age, consumption and social change, but concentrate instead on appearance and dress, exploring expenditure on clothing, hairdressing and cosmetics. These have an intimate bodily character that makes them particularly relevant to questions of identity and selfhood. They also allow us to relate our analyses to a second set of debates, concerning the body and its role in the constitution of age.

\section{Dress, the body and the presentation of self}


Work on the body has proliferated over the last two decades. Social gerontology was initially slow to engage with this, fearing to reinforce a retrogressive emphasis on the bio-medical basis of age, undermining the achievements of the Political Economy school in establishing its socially constructed nature (Estes 1989, Arber \& Ginn 1991, Phillipson 1998). With the emergence of Cultural Gerontology, however, interest has grown in the body in age, with ageing increasingly understood as the product of a complex interplay between bodily and cultural factors (Cole 1992, Cole et al 2010, Katz 1996, Gullette 1997, 2011, K.Woodward 1991, 1999, Tulle 1999, Andersson 2002, Calasanti and Slevin 2001, Hurd Clarke 2011, Gilleard and Higgs 2013, Twigg 2013).

As Shilling (2012) argues, under conditions of High Modernity, the body becomes a project - a marker of identity and source of meaning. As individuals age, however, as Featherstone and Hepworth (1991) suggest in their Mask of Ageing thesis, the body is increasingly unable to perform the youthful identity within. Surrounding consumption culture is youth-oriented, saturated with images of youthful perfection; and this has given rise to a growing commercialised culture of anti-ageing, exemplified in the popular media through make-over shows predicated on 'looking ten years younger', and adverts for anti-ageing products such as vitamins, face creams, exercise regimes, all which are based on an institutionalized fear of looking old (Gullette 1997, Calasanti 2007, Hurd Clarke 2011, Gilleard and Higgs 2013). Ageism, as Laws (1995) argued, is a bodily form of oppression, operating on and through the body. Successful ageing in the current culture becomes, as Katz (2001) argues, a matter of ageing without showing the visible signs of doing so. These processes operate particularly powerfully on women, who find themselves subject to Sontag's (1979) double standard of ageing, so that the aged female body becomes, in Woodward's (1991) terms, both invisible - in that it is no longer seen - and hypervisible - in that it is all that is seen.

Clothing provides a fruitful area in which to explore the interface between the body and social meanings attached to it. Clothes mediate between the body and the self. They are the vestimentary envelope that contains the body and presents it to the world. As such they are closely linked to identity and its expression. There is a large sociological and psychological literature exploring this (Entwistle 2000, Crane and 
Bovone 2006), though until relatively recently little that addressed age (Twigg 2013).

Other dimensions of identity or difference, such as class, gender, sexuality and ethnicity, have received greater attention, reflecting the wider neglect of age within sociological theorising (Laz 2003).

\section{Hair, cosmetics and the body in age}

Though the primary focus of this paper is dress, we also examine two related areas of expenditure - hairdressing and cosmetics. Both relate to norms of appearance, addressing the interface between visible bodily ageing and its social representation. Hair has been subject to a large anthropological and sociological literature (Firth 1973, Synott 1987, Weitz 2001, Sherrow 2006, Biddle-Perry \& Cheang 2008). In the western context, this has largely turned around questions of ethnicity and sexuality; and age has been excluded from the analysis, though recent work has begun to redress this (Ward \& Holland 2010). As Firth (1973) noted, the control of hair signals wider control of the body and the self. There is a widespread cultural unease in the West over long, free floating grey locks, that mirrors prohibitions in relation to dress around the overt display of sexuality by older women (Fairhirst 1998). Controlled, clearly managed, hair is particularly significant for older women in avoiding the status of dereliction or derangement, signalled by wild or neglected locks.

Cosmetics are a mixed category of goods encompassing make-up and face creams. During the twentieth century, the market expanded enormously, with the use of makeup achieving normative status in the west by the 1950s (Peiss 1998). Make-up and related beauty work has been subject to extensive feminist critique in terms of the double standard of beauty, the disciplinary requirements of normative femininity, and the spread of commercialised values; though postmodern feminists like Davis (1995) have detected agency, even empowerment, in their use (Hurd Clarke \& Griffin 2007, Hurd Clarke 2011). A major part of beauty work promoted by the cosmetic industry centres on fighting the signs of age, which in this sector set in early. Woodward (1991), Gullette (1997), Hurd Clarke (2011), Calasanti (2007) and Coupland (2003, 2009) have explored the ways in which ageing as a problem is discursively produced by the cosmetics industry through advertising that focuses on the value of youthful perfection and its erosion by age. 


\section{Gender: a focus on women}

This article focuses on women, reflecting the way in which fashion and appearance are constituted as feminised fields, their discourses predominately embodied in the lives of women. Cosmetics and hairdressing are similarly gendered, reflecting the differential way in which appearance norms, and their commercialization, operate in relation to men and women. Men, however, are not immune from these developments. They too make consumption choices in relation to appearance: even the least fashion conscious buy clothes (though these purchases are often made for them by women or under their influence); and with the emergence of Metrosexual Man, toiletries and fashionable hairstyles are of increased interest. To sharpen the analysis, however, we limit the data to women. In further work we will analyse spending patterns in relation to men, enabling us to explore the differentially gendered role of consumption in later life.

\section{Methodology: the Family Expenditures Survey data and the pseudo cohort analysis}

In this paper we draw on data from the UK government's Family Expenditures Survey (FES), renamed Expenditures and Food Survey (EFS) in 2001. Around 10,000 households were surveyed annually with response rates of around 60 per cent. Each member of the respondent households was asked to keep an expenditure diary for a two-week survey period. These were spread over the whole year. Unlike spending on necessities such as food, appearance-related expenditures are relatively infrequent. However, due to the unique two-week survey period which is rolled over the year, we are able not only to calculate a weekly average 'level' of spending based on the data on appearance related expenditures made within those weeks, but also calculate a weekly average 'occurrence' of such spending, based on whether such expenditures were made in the survey period. This gives a measurement of frequency of purchase, or the spending cycle.

In addition, we extracted information on household income and age of the respondents. In terms of age, we divide the data into 20 -year age bands, 16-34, 35-54, 55-74, 75+ allowing us to compare expenditure patterns of different bands. Each 20-year age band includes approximately 400-500 women. We also focus in more detail on those who are over 55, grouping them into five year age bands. Each 5-year age band 
contains roughly 100-150 women. The sample size for each cohort is small, and ideally this should be many times larger, but as will be shown later in this article, the patterns exhibited by each successive cohort has common and coherent characteristics, not just random patterns, to one another - the small sample seems adequately to manifest the patterns of the general population of older women. The data are analysed using the pseudo-cohort method. This has been used by other FES-based research, for example automobile ownership (Dargay and Vythoulkas 1999) and fashion purchasing (Majima 2006, 2008). It is 'pseudo' because it is not individual respondents but the averages of five-year age groups which are followed after the age 55. We follow cohorts/generations of women who were born in the same five-year period, starting from those born between 1881 and 1889 to those between 1946-1950, the post-war 'baby boomers'. Although the data comes from different individuals, we assume that each cohort behaves consistently as a generational group. This method allows us to explore the separate effects of generation, ageing and period

In the initial analysis, both proportion of income and frequency of purchase were examined. However, the latter presented a clearer and more consistent pattern, and forms the basis for this article. The full analysis, which includes data on proportion of household income adjusted for inflation, is available on a project website (www.clothingandage.org).

The article also draws on material from a qualitative study focused on dress, and based on interviews with older women (55-80s), magazine journalists and design directors for major retail companies. This is published as Fashion and Age: Dress the Body and Later Life (Twigg 2013).

\section{Purchasing patterns for women's clothing 1961-2011}

Two clear patterns emerge (figure 1). First, frequency of shopping across the period is associated with age, with younger women shopping for clothes more often than older. This is in line with cultural expectations about the role of clothing and appearance in women's lives. Against this, however, there is a general trend across all age groups towards greater frequency of shopping, only slightly lessening for younger groups post the 2008 recession. As a result, those over 75 are by 2011 shopping more frequently than the 16-34 group were in 1961 (some of them are indeed the 'same' 
people, having aged over the period). The trend to more frequent shopping is thus general, experienced by all, fairly steadily over the historical period.

Turning to a more detailed breakdown focussed on the over 55s (figure 2), again we observe a clear pattern towards more frequent shopping, with each cohort shopping more often than its predecessor. The oldest cohort, born between 1881 and 1885, used to buy clothing on average twice a year, but the post-war 'baby boomer' cohort buy on average nearly twice a month. We can also observe that in earlier cohorts (those born up to early 1920s) the rate of shopping remains fairly constant. Later cohorts, however, experienced a significant surge in the period 2001 and 2006, drawn into wider cultural and economic change. This is not confined to the classic 'baby boomer' group, but encompasses women in earlier cohorts (1921-25) also. Again we can observe the impact of the post 2008 recession among those groups surviving into this period.

These data need to be set in the context of changes in the fashion industry in the latetwentieth and early-twenty first centuries. The era is marked by what has been termed the 'Democratization of Fashion', described by Wilson (1985) as the process whereby the mass production of fashionably styled clothes made possible the use of fashion as a means of self-enhancement and self-expression for the majority. Exactly when this occurred is subject to debate. Some economic and dress historians trace the development to the late nineteenth and earlier twentieth centuries with the emergence of the mass clothing industry. More commonly, however, it is associated with the 1960s, and the arrival of youth-oriented fashion. But this is, in many ways, a misapprehension, a product of changing visual rather than material culture. The fashions of the sixties were peculiarly youthful, exemplified in the UK by the designs of Mary Quant and the appearance of models like Twiggy, which valorized a prepubescent look. They marked a significant change from the fifties, which presented a womanly, bourgeois ideal. The clothes of the sixties did indeed effect a major change in visual sensibility underwriting the sense of a 'Youth Quake' generation; and this identity remains central to the mythology of the period and of the 'baby boomers' as a pioneering, mould breaking generation. The strength of the sixties imagery has, however, led writers to misinterpret the changes in the fashion industry. The democratization of fashion in Wilson's terms of a mass vehicle for self 
presentation and identity formation was, we suggest in the UK, more the product of the late nineties and early two thousands than the sixties, underwritten by changes in the supply side as much as by cultural shifts.

In the post-war era, fashion in Britain was dominated by major retail multiples, such as Marks \& Spencer, operating in close conjunction with the Leeds-based manufacturers to form an effective oligopoly (Majima 2006, 2008). In the late 1990s, however, the industry was restructured, as manufacturing moved to the Far East to exploit cheaper labour. Supermarkets emerged as rivals to the traditional high street, and were able to use their buying power to produce a flood of cheap, fashion-oriented clothes. The real cost of clothes in the UK declined from 1961 to 2001 by $70 \%$ (this compares with a $20 \%$ decline in the real cost of food), and the fashion cycle intensified (Majima 2008). As a result, clothes shifted from being durables, expensive items required by everyone and bought infrequently, to consumables, cheap items bought frequently as part of active engagement with consumption. In this period we move from a world when a coat was in the 1960s a major item of expenditure expected to last several years, to one in the 2000s where single season coats of fashionable cut and colour became widely available in supermarkets and other low cost retailers.

This massive expansion of productive capacity required new markets. As the youth market became saturated, retailers sought to extend the scope of 'fashionability' to new social groups. In the early twenty-first century this has meant children and older people, both of whom have increasingly been brought into the orbit of fashion. Research interviews in the UK with mainstream fashion retailers in the form of Marks \& Spencer and George at ASDA, the UK branch of WalMart, as part of a qualitative study of the fashion industry confirmed how they identified older women in this period as a distinctive market that was ripe for development (Twigg 2013) .

We thus have a general trend towards more frequent shopping across all age groups over the historical period. Older women are thus drawn into what is a general cultural phenomenon, and one reflected also in the responses of retailers seeking out new markets. This supports the thesis that the lives of older people are increasingly integrated into the mainstream through consumption. The data do not, however, 
support the assertion of the 'baby boomers' as a strategic generation. The behaviour of this cohort does not appear to be distinctively different. In so far as there is a break between cohorts, it is in relation to a general expansion of shopping that occurred in 2000s, where cohorts born after 1921-25 were also drawn in. But these encompass more than just the 'baby boomer' generation, and suggest the influence of general economic factors rather than specific cohort ones.

\section{Purchasing patterns on hairdressing 1961-2011}

Turning now to hairdressing (figure 3), we observe during the period a striking shift in which greater frequency of attendance moves from being associated with younger to older women. In 1961 women in 16-54 were the most frequent attenders, with a marked falling off among those over 75. By 2011, the pattern is reversed and the most frequent attenders are those over 75. This is partly the product of declining frequency among the younger groups, but it also reflects increased attendance by older. The finer grain generational data focused on those over 50 (figure 4) shows that it is the cohorts born up until 1920 who display a pattern of increased frequency; the high tide being the generation 1916-20. After that, there is a falling back, reflecting the coming through of cohorts less attached to frequent salon attendance.

We can make sense of this pattern in terms of changes in the nature of hairdressing, in particular the passing through of a shampoo-and-set generation. During the 1950s and 60s hairdressers proliferated in the UK (Smith 2008) providing distinctive salon-based styles centred on the weekly shampoo and set. This was the era of rollers, setting lotion, backcombing and hair laquer. Though many women pursued these looks through hairdressing at home, the effect was most fully achieved by salon attendance; and 'a salon finish' was part of the desired outcome. In subsequent decades, hairstyles changed. In the seventies, long, freefloating hair, largely unmanaged by hairdressers, was fashionable among young women. The 1980s saw a shift towards wash-and-go styles that emphasised cut, and allowed for easy care at home (Cox 1999). This was linked to the steady rise in frequency of hair washing, no longer simply a weekly affair, and the shift in the UK towards daily showering that required easy home management of hair (Smith 2007). The pensioner's hair-do which is such a marked feature of the appearance of many women in their seventies and eighties in the UK today can, thus, be understood as a fossilised version of the 1950s and 60s 
salon look. These cohorts have remained loyal to the pattern of salon attendance in which they were socialised earlier in their lives and, to some extent, to the styles that went with it.

There are, however, additional factors underlying this pattern. Women as they age find hair difficult to manage, as it becomes thinner and more brittle, making normative hair styles harder to achieve. Washing demands a degree of flexibility, particularly if undertaken as traditionally at a basin; and styling requires the capacity to raise the arms above the shoulders. In this context the salon presents the means of maintaining personal appearance against the depredations of ageing. Furman (1997) in her classic account of a New Jersey hair salon emphasises how attendance enabled older women maintain personal and social identity, demonstrating their continued engagement with the disciplinary practices of femininity, staving off accusations of self neglect. Salons are also opportunities for social and physical contact. Those catering for this group in the UK are typically local, sited in parades of shops, often owned and staffed by people living in the neighbourhood; and they offer an opportunity for the kind of recurring social contact valued by older women, many of whom live alone (Patterson 2007). Hairdressing is also a form of body work (Wolkowitz 2002, Twigg et al 2011) involving physical touch of a pleasant and endorsing kind. As such it stands in contrast to the bodily interventions that many older people are forced to endure as part of declining health.

There are, therefore, a number of reasons why older women might seek out relatively frequent hairdressing services, and be willing to dedicate relatively large parts of their relatively low incomes to them. But they are not, by and large, reasons that endorse the account of the 'baby boomers' as a pioneering generation. As we noted, they were not the generation involved in higher consumption: it was previous cohorts, and associated more with distinctive styles rather than orientation to consumption as such. The character of this consumption also does not fit the 'baby boomer' thesis. It is more about constraints imposed by the body and by the social circumstances of growing old, than any celebrationist engagement with self-fashioning.

The upsurge of engagement with clothing shopping was, as we saw, stimulated by supply side developments in the form of the massive influx of cheap clothing and a 
major reduction in price. Hairdressing, by contrast, is a service industry, produced and consumed in parallel; where it is not possible to make the same efficiency gains, and where costs are primarily set by wage rate inputs. Though these have traditionally been low, reflecting the gendered nature of the labour market, they act as a brake on cost reduction (Drucker et al 2005). The sector is dominated in the UK by small independent providers, so that in so far as there have been supply-side developments, they are of a modest type, such as pensioner discount days.

\section{Purchasing patterns on Cosmetics 1961-2011}

Turning now to cosmetics (figure 5), in the 1960s it was the young who shopped most frequently, with a decline in levels across older groups. Low engagement was particularly marked among those over 75, who were rarely involved in such shopping. By 2011, however, the pattern has shifted, and those shopping most often were those in the mid cohorts. Turning to the more detailed analysis of cohorts of the over $55 \mathrm{~s}$ (figure 6), we can see a steady movement towards more frequent shopping across each successive birth cohort as it enters the age of 55+, though as these cohorts themselves age, there a general decline in frequency of purchase.

Cosmetics are a mixed category, encompassing both make-up and face creams. It is likely that it is developments in relation to the latter that underpin the expansion among the mid and later age groups. The period of the late 1990s to early 2000s saw a major expansion in the anti-ageing market, linked to parallel developments in antiageing medicine within the closely associated pharmaceutical industry (Vincent et al 2008). Coupland $(2003,2009)$ has analyzed the discursive strategies used by cosmetic companies since the late nineties to develop the market for anti-ageing products. These adverts equate ageing with the appearance of age, which is presented as something shameful, for which the individual is personally responsible, but that can be prevented or mitigated by the use of anti-ageing creams. Evidence from marketing reports (Mintel 2004, Keynote 2009) suggests a strong growth in the sector, with sales of facial skincare increasing in value by $10.2 \%$ in 2008 , largely driven by the premium price anti-ageing formulations. Market penetration of face creams and lotions is described as highest among women in the 65+ age range. These products have a high degree of brand awareness, and their promotion has been strongly led by the giant toiletry corporations which have used glossy advertising aimed at women in 
middle and later years to develop the market. Keynote (2009) reports $£ 66.1$ million a year spent in 2008 the UK on such advertising, led by L'Oreal, Olay and Garnier.

Over the historical period, therefore, we observe a pattern whereby cosmetic purchase moves from being associated with younger women to middle aged and older ones. This is in line with the evidence concerning the growing significance of the mature market created through active promotion of high-value anti-aging products, once again pointing to the importance of producer-led effects. In relation to the reconstitution of ageing theory, there is - again - no support for the 'baby boomers' as special generation, but there is support for a more general shift over time towards greater involvement by older women in these areas of appearance.

\section{Consumption and ageing revisited}

We now return to the debate on consumption and age. As will be clear our data do not support the idea of the baby boomers as a 'special' cohort or strategic generation. Across the three sectors, their responses do not appear significantly different from previous cohorts; there is little evidence of a radical break or discontinuity. The one area where there is a strong generational or cohort effect is hairdressing, but here, as we noted, it is the 'wrong' generation: the distinctive pattern relates not to 'baby boomers' but those born earlier in the century who came to maturity in the fifties and sixties; and it relates more to the historic passing through of a particular style, and the habits associated with it, than wider changes in the nature of old age.

If we look in greater detail at Higgs and colleagues' article (2009), they do demonstrate growing engagement in consumption by older people, but this can be explained as much by period as cohort effects. Their strongest example relates to leisure where they show increased proportion of expenditure being spent in households headed by a retired person. When compared with other categories, households headed by a retired person in their study are indeed closer to the employed and self-employed than the unemployed. But the pattern is one that continues over time: it does not increase in the way that the thesis might suggest. In other areas of less discretionary spending, like food and fuel, 'retired' households are closer to the 'unemployed' than those in work, suggesting a continuity with older patterns of constraint. Finally there is no evidence in their pseudo-cohort analysis of significant 
generational influences. There is a long-term trend observable as each cohort reaches old age, but no generational breaks. The last cohort they trace (those born 1940-44) shows no distinctively different pattern from previous ones.

In related work (Jones et al 2008), they compare the ownership of key consumer durables such as TVs, fridges, DVDs, between household types. This shows the steady spread of ownership among the retired, but again reflecting a general trend rather than the response of specific cohorts, supporting period rather than generational effects. Though they assert that 'consumption patterns in later life are influenced by the generational habitus of differing cohorts who enter retirement between the 1960s and the present day' (p102), the data do not really support this. There is a discordance between the sophistication of their argument in relation to 'generational habitus' and the evidence they can muster to support this account.

Part of the problem is that too many writers have been transfixed by the terminology of the 'baby boomers'. The academic debate has been dominated by the perceptions of American authors, where baby boomer describes a much longer cohort. In the UK the term has achieved currency in market research and the media where it allows for reference to the imagery of the Sixties - yet again. How far the claimed features of this generation are borne out in concrete behaviour, however, remains more questionable. Furthermore as we noted, 'baby boomer' is an implicitly classed term, reflecting the patterns and aspirations of particular groups; its relevance is thus narrower than the media's enthusiasm suggests.

Much of the baby boomer 'debate' is speculative, based in rhetoric about what the baby boomers 'will' or 'will not' do, pertaining more to futurology or journalism than academic analysis. In relation to theories about ageing, evidence is as yet limited. The 'baby boomer' cohort is only in its sixties; and we have no knowledge of them in their seventies or eighties, decades that will be crucial for any redefinition of age.

What we can observe, however, is behaviour over the historical period from the 1960s. Here there is clear evidence for steady acceleration of shopping frequency for clothes among older women that mirrors trends among younger groups. There is also some evidence for greater engagement of older women with hairdressing, but we noted how 
this was associated with a specific cohort. It is in relation to cosmetics, however, we have the clear movement towards greater, and differential, engagement by older women. Together these shifts can indeed be interpreted as supporting the idea of greater engagement by older people in the world of consumption.

In this shift, however, we point to the significance of supply-side developments, rooted in the economy, as much as changes in the meaning or perceptions of old age, or the values of new cohorts coming through. The major shift in relation to clothing was rooted in changes in production, with the introduction of mass cheap fashion and the development of a true democratization of fashion. In relation to cosmetics, the key driver was once again producer-led developments in which new markets were created. Hairdressing is a less clear case, complicated perhaps by the dominance of small independent providers tied to a local service economy; but here we do not observe the clear growth of involvement that is evident in the other sectors.

\section{Conclusion}

As will be clear, our analysis does not support the mythology of the 'baby boomers' as a strategic generation, or a cohort that pioneered cultural change. Rather, as they have aged they have been drawn into changing historical circumstances of the period; and their behaviour reflects that. They have, of course, contributed to that historical change, but there is no strong evidence that this has been primarily driven by a generational habitus. Part of the problem, as we have noted, has been the preoccupation by the media with the idea of the 'baby boomers', encouraged by fascination with the visual imagery of the Sixties. In relation to dress this has misled analysts into dating the democratisation of fashion to an earlier period than is actually the case. In reality it is only in the early twentieth-first century that frequent shopping and fast moving fashion were extended to the majority of the British population. Older women are indeed increasingly engaged with fashion in the early twentieth-first century, but in this they are responding to the mood of the times and the economic opportunities of the period, just like everyone else.

\section{References}

Age UK (2010). The Golden Economy: The Consumer Marketplace in an Ageing Society. London: Age UK. 
Anderson, M. (1985). The emergence of the modern life cycle in Britain. Social History, 10 (1); 69-87.

Andersson, L. (ed) (2002). Cultural Gerontology. Westport: Auburn House.

Arber, S. and Ginn, J. (1991). Gender and Later Life: A Sociological Analysis of Resources and Constraints. London: Sage.

Bauman, Z. (2000). Liquid Modernity. Cambridge: Polity Press.

Biddle-Perry, G. and Cheang, S. (eds) (2008). Hair: Styling, Culture and Fashion. Oxford: Berg.

Biggs, S., Phillipson, C., Leach, R. and Money, A-M. (2007). The mature imagination and consumption strategies: age and generation in the development of a United Kingdom baby boomer identity. International Journal of Ageing and Later Life $2,13-30$.

Calasanti, T. (2007). Bodacious berry, potency wood and aging monster: gender and age relations in anti-aging ads. Social Forces, 86 (1); 335-55.

Calasanti, T. M., and Slevin, K. F. (2001). Gender, Social Inequalities, and Aging. New York: Alta Mira Press.

Cole, T. C. (1992). The Journey of Life: A Cultural History of Aging in America. Cambridge: Cambridge University Press.

Cole, T.C., Ray, R.E, Kastenbaum, R. (eds) (2010). A Guide to Humanistic Studies in Aging: What Does it Mean to Grow Old. Baltimore: John Hopkins University Press

Coupland, J. (2003). Ageist ideology and discourses of controlling skin care product marketing. In J.Coupland and R.Gwyn (eds) Discourse, the Body and Identity, London: Palgrave.

Coupland, J. (2009). Time, the body and the reversibility of ageing: commodifying the decade Ageing \& Society, 29, 953-79.

Cox, C. (1999). Good Hair Days: A History of British Hairstyling. London: Quartet Books.

Crane, D. and Bovone, L. (2006), 'Approaches to material culture: the sociology of fashion and clothing,' Poetics, 34, 319-33.

Davis, K. (1995). Reshaping the Female Body: the Dilemma of Cosmetic Surgery. New York: Routledge. 
Dargay, J. M. and Vythoulkas, P. C. (1999). Estimation of a dynamic car ownership model: a pseudo-panel approach. Journal of Transport Economics and Policy, 33, 293-4.

Drucker, J., White, G. and Stanworth, C. (2005). Coping with wage regulation: implementing the national minimum wage in the hairdressing business. International Small Business Journal, 23(1); 5-25.

Edmunds, J and Turner, B. S. (2002). Generations, Culture and Society. Buckingham: Open University.

Entwistle, J. (2000). The Fashioned Body: Fashion, Dress and Modern Social Theory. Cambridge: Polity.

Estes, C. L.(1979). The Ageing Enterprise. San Francisco: Jossey Bass.

Fairhurst, E. (1998). "Growing old gracefully" as opposed to "mutton dressed as lamb": the social construction of recognising older women. In S. Nettleton and J.Watson (eds) The Body in Everyday Life, London: Routledge.

Featherstone, M. and Hepworth, M (1991). The mask of ageing and the postmodern life course. In M.Featherstone, M. Hepworth and B. S. Turner (eds) The Body: Social Process and Cultural Theory, London, Sage.

Firth, R. (1973). Symbols: Public and Private. London: Allen \& Unwin.

Furman, F.K. (1997). Facing the Mirror: Older Women and Beauty Shop Culture. New York: Routledge.

Giddens, A. (1991). Modernity and Self-identity: Self and Society in the Late Modern Age. Palo Alto: Stanford University Press.

Gilleard, C. and Higgs, P (2000). Cultures of Ageing: Self, Citizen and the Body. London: Prentice Hall.

Gilleard, C. and Higgs, P. (2002). The third age: class, cohort or generation? Ageing \& Society, 22, 369-82.

Gilleard, C.and Higgs, P. (2007). The third age and the baby boomers: two approaches to the social structuring of later life. International Journal of Ageing and Later Life, 2 (2); 13-30.

Gilleard, C.and Higgs, P. (2013). Ageing, Corporeality and Embodiment. London: Anthem Press.

Gullette, M. M. (1997). Declining to Decline: Cultural Combat and the Politics of Midlife. Charlottesville: University Press of Virginia. 
Gullette, M.M. (2011). Agewise: Fighting the New Ageism in America. Chicago: University of Chicago Press.

Higgs, P.F., Hyde, M., Gilleard, C.J., Victor, C.R., Wiggins, R.D., and Jones, I.R. (2009). From passive to active consumers?: Later life consumption in the UK from 1968 to 2005. The Sociological Review, 57 (1); 102-24.

Hurd Clarke, L. and Griffin, M. (2008). Visible and invisible ageing: beauty work as a response to ageism. Ageing \& Society, 28, 653-74.

Hurd Clarke, L. (2011). Facing Age: Women Growing Older in Anti Ageing Culture. Lanham, Maryland: Rowman \& Littelfield.

Jones, I. R., Hyde, M., Victor, C.R., Wiggins, R.D. Gilleard, C. and Higgs, P. (2008). Ageing in a Consumer Society: From Passive to Active Consumption in Britain. Bristol: Policy Press.

Karisto, A. (2007). Finnish baby boomers and the emergence of the Third Age. International Journal of Ageing and Later Life, 2 (2); 91-108.

Katz, S. (1996). Disciplining Old Age: The Formation of Gerontological Knowledge. Charlottesville: University Press of Virginia.

Katz, S. (2001), 'Growing older without aging?: positive aging, anti-ageism, and antiaging,' Generations, 2001: 27-32.

Keynote (2009). Toiletries: Market Report Plus. London: Keynote

Laws, G. (1995). Understanding ageism: lessons from feminism and postmodernism. Gerontologist, 35 (1); 112-18.

Laz, C. (2003). Age embodied. Journal of Aging Studies, 17, 503-519.

Majima, S. (2006). Fashion and the Mass Consumer Society in Britain, c. 1951-2005. Unpublished D. Phil. Thesis, University of Oxford.

Majima, S. (2008). 'Fashion and frequency of purchase: womenswear consumption in Britain, 1961-2001', Journal of Fashion Marketing and Management, 12, 4, 502-517.

Mintel (2004). Essentials: Premium Skincare. London: Mintel.

Öberg, P. and Tornstam, L. (1999). Body images among men and women of different ages. Ageing \& Society, 19, 629-644.

Öberg, P. and Tornstam, L. (2001). Youthfulness and fitness - identity ideals for all ages?. Journal of Ageing and Identity, 6 (1); 15-29.

Paterson, M. (2006). Consumption and Everyday Life. London: Routledge. 
Patterson, P. G. (2007). Demographic correlates of loyalty in a service context. Journal of Services Marketing, 21 (2); 112-21.

Peiss, K. (1998). Hope in a Jar: The Making of America's Beauty Culture. New York: Metropolitan Books.

Phillipson, C. (1998). Reconstructing Old Age: New Agendas in Social Theory and Practice. London: Sage.

Phillipson, C. (2007). Understanding the baby boomer generation: comparative perspectives. International Journal of Aging and Later Life, 2 (2); 7-11.

Phillipson, C. (2013). Ageing. Cambridge: Polity.

Sherrow, V. (2006). Encyclopaedia of Hair: A Cultural History. Westport, Conn: Greenwood Press.

Shilling, C. (2012 $3^{\text {rd }}$ ed). The Body and Social Theory. London: Sage.

Smith, K. (2008). From style to place: the emergence of the ladies hair salon in the twentieth century.In G. Biddle- Perry and S. Cheang, (eds) Hair: Styling, Culture and Fashion, pp55-65, Oxford: Berg.

Smith, V. (2007). Clean: A History of Personal Hygiene and Purity. Oxford: Oxford University Press.

Sontag, S. (1979). The double standard of ageing. In V. Carver and P Liddiard (eds) An Ageing Population, New York: Touchstone.

Stewart, A. J., and Torges, C. M. (2006). Social, historical and developmental influences on the psychology of the baby boom at midlife. In S. Whitbourne and S. L. Willis (eds) The Baby Boomers Grow Up: Contemporary Perspectives on Midlife, Mahwah, HJ: Lawrence Erlbaum Associates.

Synnott, A. (1987). The Body Social: Symbolism, Self and Society. London: Routledge. Tomassini, C. (2005). Focus on Older People: Demographic Profile. London: Office of National Statistics.

Twigg, J. (2013). Fashion and Age: Dress, the Body and Later Life. London: Bloomsbury.

Twigg, J., Wolkowitz, C., Cohen, R.L. and Nettleton, S. (eds) (2011)

'Conceptualising body work in health and social care,' Sociology of Health and Illness, 33, 2, 171-88.

Tulle, E. (1999). Growing old and resistance: the new cultural economy of old age?. Ageing and Society, 19, 281-299. 
Vincent, J., Tulle, E. and Bond, J. (2008). The anti-ageing enterprise: science, knowledge, expertise, rhetoric and values. Journal of Aging Studies, 22, 291-94.

Walker, A. (2012). The new ageism. Political Quarterly, 83, 4, 812-19.

Ward, R and Holland, C. (2010). If I look old, I will treated old': hair and late-life image dilemmas. Ageing \& Society, 31, 2, 288-307.

Weitz, R. (2001). Women and their hair: seeking power through resistance and accommodation. Gender \& Society, 15, 5, 667-86.

Willetts, D. (2010). The Pinch: How the Baby Boomers Stole Their Children's Future. London: Atlantic Books.

Wilson, E. (1985). Adorned in Dreams: Fashion and Modernity. London: Virago.

Woodward, K. (1991). Aging and Its Discontents: Freud and Other Fictions. Bloomington: Indiana University Press.

Woodward, K. (ed) (1999). Figuring Age: Women, Bodies, Generations. Bloomington: Indiana

Wolkowitz, C. (2002). The social relations of bodywork. Work, Employment and Society, $16(3) ; 497-510$. 


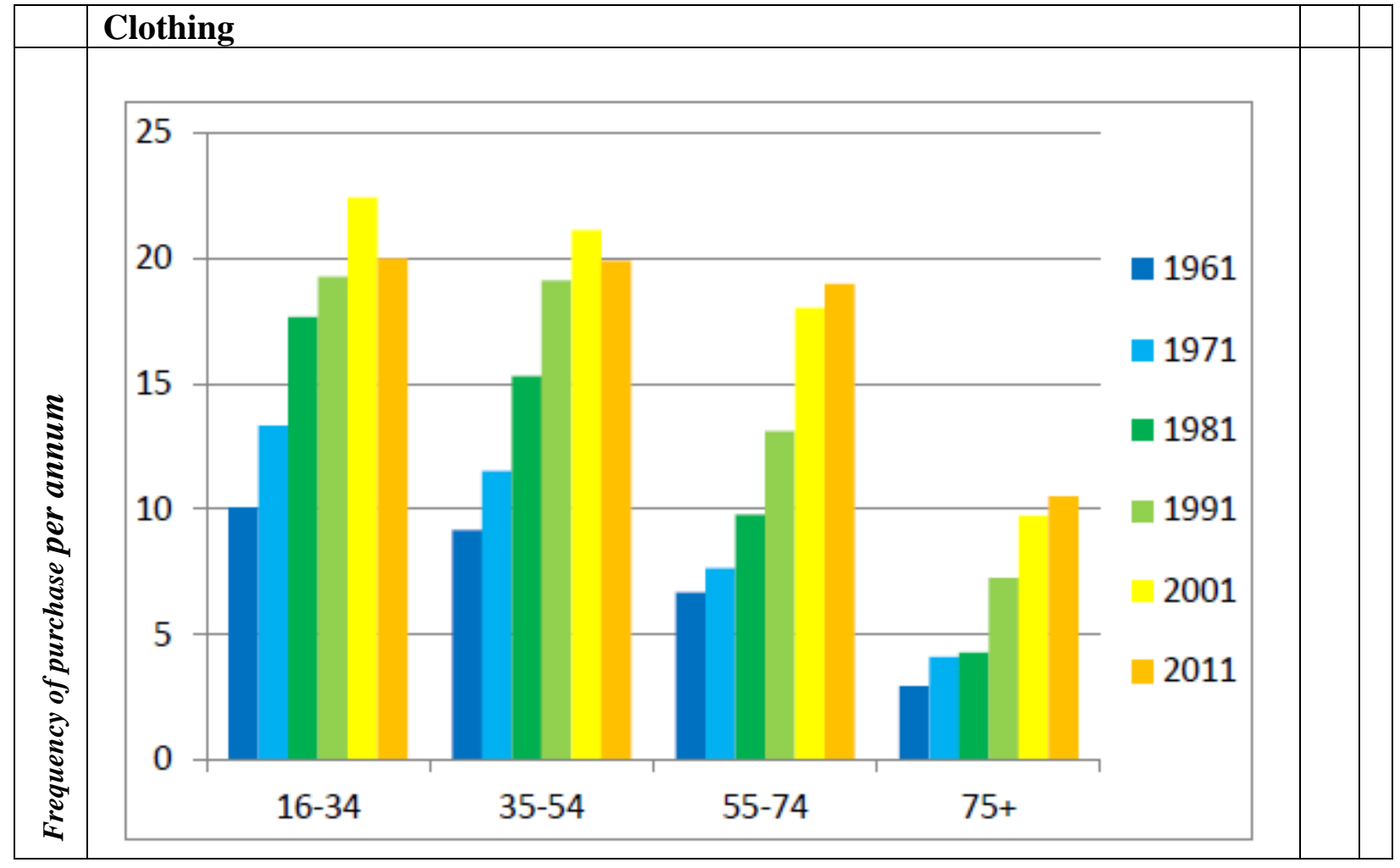

Figure 1: Frequency of purchase of clothing per annum, by 20-year age groups 
Figure 2: Frequency of clothing purchase per annum, by birth cohort and year 


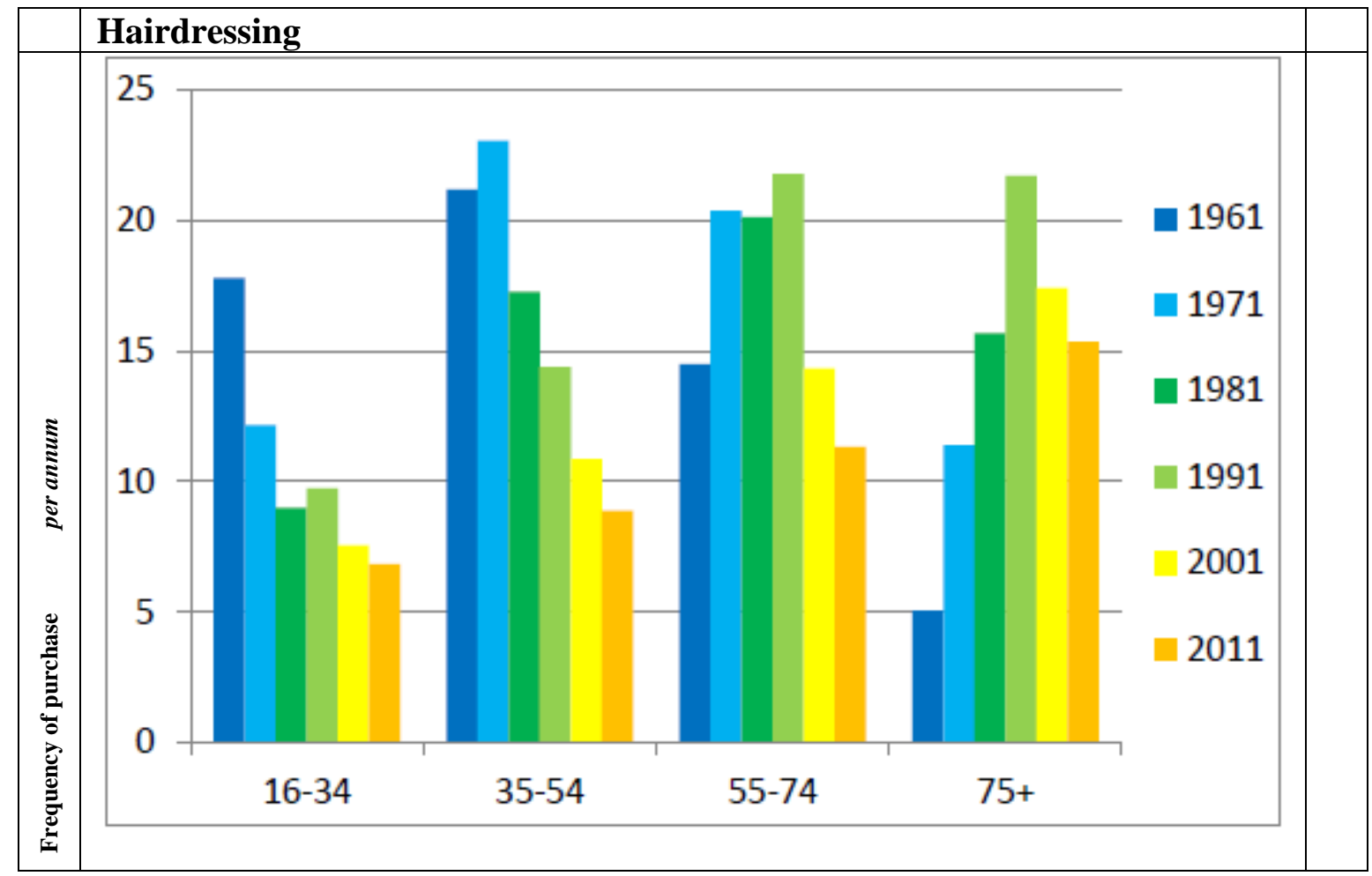

Figure 3: Frequency of visits to hairdresser per annum, by 20-year age group 


$$
\text { : }
$$

Figure 4: Frequency of visits to hairdressers, by birth cohort and year 


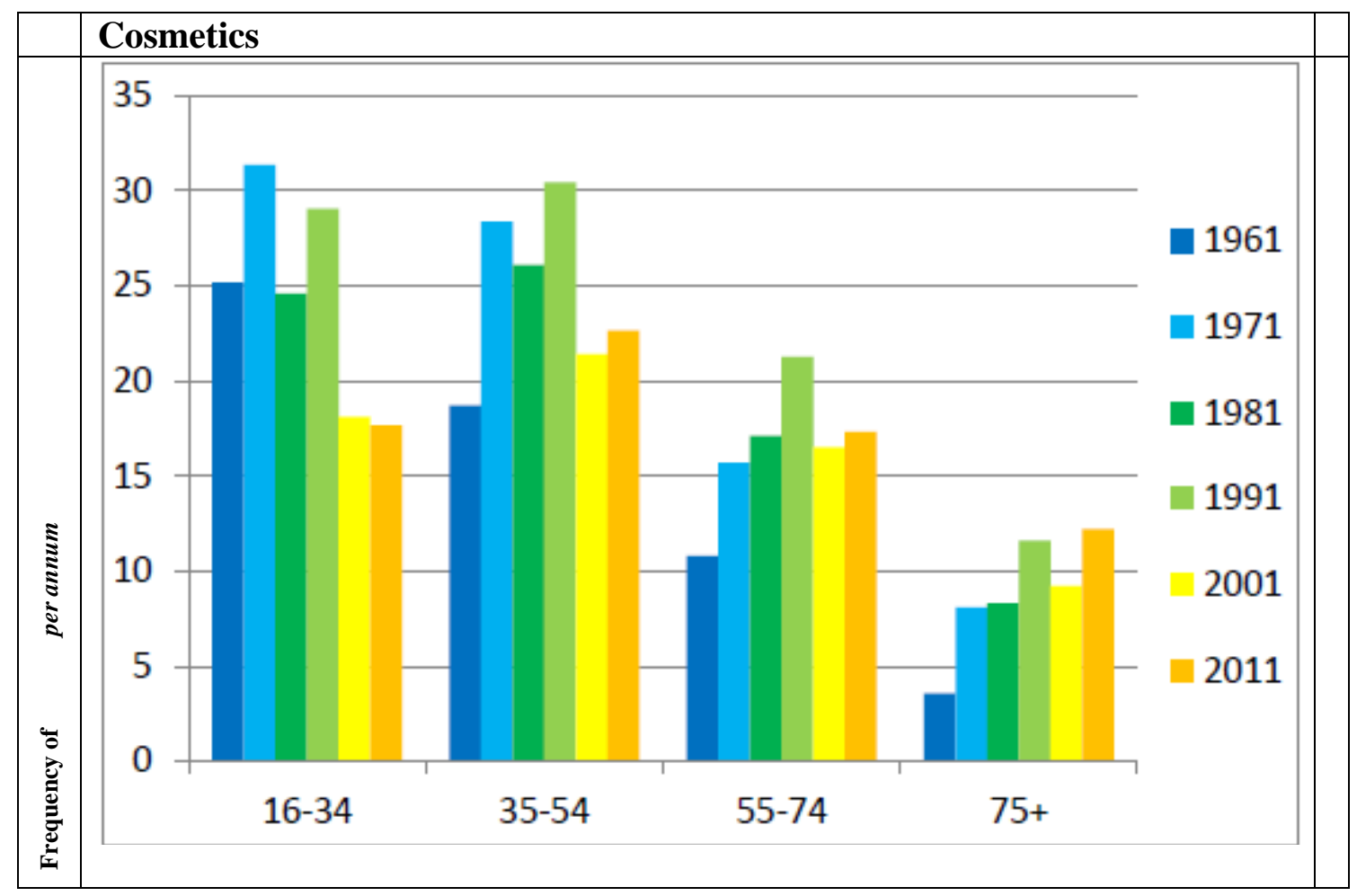

Figure 5: Frequency of purchase of cosmetics per annum, by 20-year age group. 


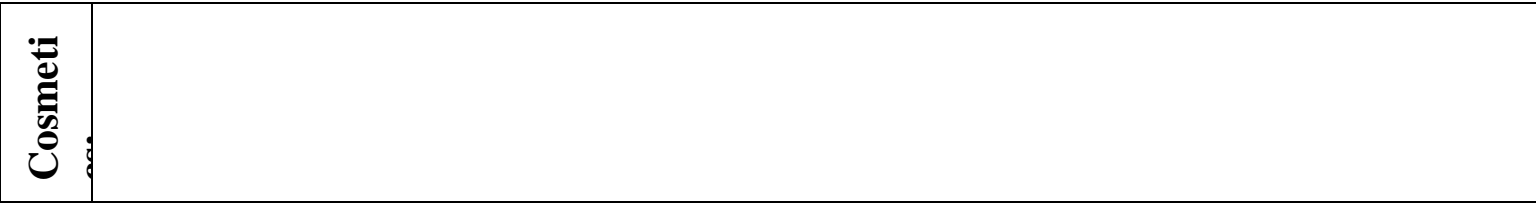

Figure 6: Frequency of purchase of cosmetics, per annum, by birth cohort and year 